\title{
XPS \& FTIR Study of Adsorption Characteristics Using Cationic and Anionic Collectors on Smithsonite
}

\author{
Hosseini S. Hamid ${ }^{*}$ and Forssberg Eric \\ Division of Mineral Processing, \\ Department of Chemical Engineering and Geosciences \\ Luleå University of Technology, \\ SE -971 87 Luleå, Sweden \\ *Corresponding author: Tel.:+46-920- 491784; fax: +46-920-97364 \\ E-mail address: hamid.hosseini@ltu.se
}

\section{ABSTRACT}

The adsorption of cationic and anionic collectors on the surface of smithsonite was studied using diffuse reflectance FTIR (DRIFT) and X-ray photoelectron spectroscopy (XPS or ESCA) techniques.

The FT-IR spectra studies of smithsonite conditioned using DDA (dodecylamine) show the presence of $\mathrm{RNH}_{2}$ on the surface of smithsonite and accordingly the adsorption of DDA. XPS results show the presence of a ZnS layer on the surface after sulphidising in amine adsorption. The appearance of the $N(1 s)$ signal of the amine groups and $S(2 p)$ signal of ZnS which increased in the intensity of the signal of $C$ (1s) peak by adsorption of DDA on smithsonite. The presence of $\mathrm{COO}^{-}$on the surface of smithsonite after oleic acid treatment confirmed the adsorption of OA (oleic acid) onto the surface. The most adsorption occurs at around $\mathrm{pH} 10$, when $\mathrm{RCOO}^{-}$is predominant in solution and has ample opportunities for interaction with the mineral surface.

The appearance of $\mathrm{CS}_{2}$ on the surface of smithsonite exposes the adsorption of KAX (potassium amyl xanthate) onto surface. XPS results confirm the presence of ZnS layer on the surface after sulphidising in amine adsorption and also the transferring the surface to CuS in KAX adsorption. It is suggested that copper cations exchange with those of zinc during copper activation of smithsonite such as activation of sphalerite.

Keywords: Smithsonite; Anionic collector; Cationic collector; FTIR; XPS

\section{INTRODUCTION}

A large investigation was devoted to finding the best collector for the recovery of smithsonite. Several amines were tested and a dodecylamine derived from vegetable oil proved to be the most suitable [1]. However, there is no complete analogy between the properties of metal ions in solution and on mineral surfaces, due to the various degrees of coordination saturation caused by surrounding anions. In the case of carbonate minerals 
such as smithsonite, the surface activity of the mineral in water increases, and the adsorption of water molecules resemble chemisorption. This high activity to water dipoles is one of the main reasons for the low natural floatability of smithsonite compared with sphalerite. Hence, there is a lower possibility of effective adsorption of flotation reagent molecules on the smithsonite surface [2].

The design of reagent regimes for a selective hydrophobization of mineral surfaces by means of collectors is still an important subject in flotation research. The ionic surfactants are used with different structures for the selective flotation due to hydrophobization of the minerals. These collectors are adsorbed through electrostatic interaction of the polar group of the surfactant molecules with ions of the minerals' surface [3].

The most important sources of zinc ore have been the oxidised zinc minerals e.g. smithsonite $\left(\mathrm{ZnCO}_{3}\right)$, willemite $\left(\mathrm{Zn}_{2} \mathrm{SiO}_{4}\right)$, hydrozincite $\left(2 \mathrm{ZnCO}_{3} 3 \mathrm{Zn}(\mathrm{OH})_{2}\right)$, zincite $(\mathrm{ZnO})$ and hemimorphite $\left(\mathrm{Zn}_{2} \mathrm{SiO}_{3} \mathrm{H}_{2} \mathrm{O}\right)$. The flotation of oxidised lead and zinc, in particular oxidized zinc minerals, is much more difficult than the flotation of corresponding sulphide minerals [4].

Many researchers suggested that the oxidised zinc ores can be collected by flotation with long chain primary amines as collector after sulphidizing with sodium sulphide. They stressed that hexyl and amyl xanthate can be used for collecting smithsonite, but in practice the process is not selective enough. The amount of sulphidizing reagent and $\mathrm{pH}$ of the pulp must be carefully controlled. Sodium sulphide is a preferred soluble sulphide in comparison to other sulphides e.g. calcium sulphide, barium sulphide and ammonium polysulphide [5-8].

The activating effect of sodium sulphide is strongly time dependent. An increase in sulphidisation leads to an increase in the hydrophobicity of the mineral surface. Excess of sodium sulphide acts as a depressant for oxidised lead and zinc minerals because the adsorption of divalent sulphide ions on the surface of lead oxide minerals increases the negative charge which prevents the adsorption of collector [9]. XPS and FTIR have been found to be useful techniques for elucidating the surface properties of solids, which may be relevant in applied aspects of mineral processing [10].

In the present investigation, the adsorption behaviour effects of various amounts of cationic and anionic collectors on pure smithsonite surfaces was verified using diffuse reflectance FT-IR and XPS studies.

\section{MATERIALS AND METHODS}

\section{Materials}

The crystalline smithsonite samples (90\% purity) were obtained from the Angooran zinc deposit, Iran. The XRF chemical analysis showed the pure sample contains $58.50 \%$ 
$\mathrm{ZnO}, 0.26 \% \mathrm{Fe}_{2} \mathrm{O}_{3}, 0.29 \% \mathrm{SiO}_{2}, 0.84 \% \mathrm{CaO}, 3.41 \% \mathrm{Na}_{2} \mathrm{O}, 1.06 \% \mathrm{PbO}, 0.34 \%$ others, $35.30 \%$ L.O.I (Loss of ignition). The mineral samples were wet ground in a porcelain mill to obtain $-5 \mu \mathrm{m}$ size fractions. This final product $(-5 \mu \mathrm{m})$ was employed for FT-IR and XPS measurements.

\section{Reagents}

Dodecylamine (99\% purity) was obtained from Fluka Chemie, Switzerland. Potassium amyl xanthate with 90\% purity was purchased from Shandong Qixia Flotation Reagent Co., Ltd, China and was purified by recrystallization from acetone. Oleic acid (99.9\% purity), sodium sulphide and copper sulphate anhydrous (99\% purity) was procured from Merck KGaA, Germany. Analytic grade $\mathrm{HCl}$ and $\mathrm{NaOH}$ were used for $\mathrm{pH}$ adjustment in all experiments. Deionised water (specific conductance, $0.4-0.7 \mu \mathrm{S} \mathrm{cm}{ }^{-1}$ ) was used in all experiments.

\section{Diffuse Reflectance FTIR Measurements}

The mineral suspensions of smithsonite with $-5 \mu \mathrm{m}$ particle size and $1 \%$ solid ratio were first conditioned for 2-4 minutes together with $\mathrm{NaOH}$ or $\mathrm{HCl}$ as $\mathrm{pH}$ regulating reagent in the presence of various activators. Sodium sulphide and copper sulphate were used in KAX treatment whereas sodium sulphide as sulphidising agent was used in amine treatment. Then the samples were conditioned for 5-10 minutes with different reagents such as dodecylamine, oleic acid and KAX. The infrared spectra were obtained for all pure samples on the air dried $-5 \mu \mathrm{m}$ mineral powders before recording the DRIFT infrared spectrum.

The FTIR spectra were registered with a Perkin Elmer Spectrum 2000 FTIR-Diffuse reflectance spectrometer. This instrument is capable of data collection over a wave number range of $370-7800 \mathrm{~cm}^{-1}$ and can be configured to run in single-beam, ratio or interferogram modes. About $10 \%$ by weight of the solid samples were mixed with spectroscopic grade $\mathrm{KBr}$ with a refractive index of 1.559 and a particle size of 1-5 $\mu \mathrm{m}$. These spectra were recorded with 200 scans measured at $4 \mathrm{~cm}^{-1}$ resolution.

\section{$X$-ray Photoelectron Spectroscopy (XPS) Measurements}

$\mathrm{X}$-ray photoelectron spectroscopy (XPS) is one of the major techniques in basic research of flotation-related surface studies of different minerals. The advantages of the method, in general, are good surface sensitivity, rather straightforward elemental and chemical state analysis and reliable quantification of the data.

The XPS spectra were obtained with an Axis Ultra electron spectrometer manufactured by Kratos Analytical. Ltd, UK. The vacuum in the sample analysis chamber was $10^{-9}$ Torr. A value of $285.0 \mathrm{eV}$ was adopted as standard C (1s) binding energy. The measurements were performed on the samples used in FTIR measurement. 


\section{RESULTS AND DISCUSSION}

\section{FT-IR Studies of Pure Smithsonite}

The smithsonite spectrum displays several bands in the region 4000-400 $\mathrm{cm}^{-1}$, Table 1 shows the assignment of pure smithsonite bands according to literature and experimental data. When smithsonite is immersed in water there are carbonate, hydroxyl carbonate, and hydroxide. $\mathrm{H}_{2} \mathrm{O}$ group physically adsorbs on the surface of the mineral. The amount of physically adsorbed water decreased by $\mathrm{Na}_{2} \mathrm{~S}$ treatment which transforms into $\mathrm{ZnS}$. Marabini and Rinelli stressed that there are no significant variations after sulphidization and this is expected because the $\mathrm{ZnS}$ and $\mathrm{ZnCO}_{3}$ bands are very similar. The $\mathrm{ZnCO}_{3}$ species disappears after sulphidization and completely forms the $\mathrm{ZnS}$ coating in the case of very high $\mathrm{Na}_{2} \mathrm{~S}$ concentrations as a form of one monolayer or a little more [11]. The reference DRIFT spectra of smithsonite, dodecylamine, KAX, sodium oleate, copper sulphate and sodium sulphide are shown in Fig. 1.

Table 1- Assignment of pure smithsonite bands according to literature and experimental data (Wave number in $\mathrm{cm}^{-1}$ )

\begin{tabular}{cl}
\hline FT-IR experiment data & \multicolumn{1}{c}{ Reference data } \\
\hline 744.01 & $743[12], 742.9[13], 744[14], 745[15]$ \\
840.0 & $841[13]$ \\
868.7 & $870[13-15], 874.1[12]$ \\
1089.88 & $1093[12], 1096[15]$ \\
1175 & $1170[15]$ \\
1435.46 & $1427[14-15], 1440[12-13]$ \\
1812.03 & $1830-1790[13], 1816[15], 1810[14]$ \\
2492 & $2493[14-15]$ \\
2850 & $2850[15]$ \\
2920 & $2924[15]$ \\
\hline
\end{tabular}

\section{Adsorption of Dodecylamine}

Since the functional groups of the collector absorption region closely match to the strong absorption region of smithsonite, it is difficult to identify any bands under mono layer adsorption. The absorption bands are often highly coupled and therefore it is not always possible to assign them to one specific vibration.

Figure 2 shows the spectra of pure smithsonite treated with sodium sulphide solution $\left(2.6 \times 10^{-2} \mathrm{M}\right)$ at $\mathrm{pH} 11.5$ with increasing initial concentration of dodecylamine. 


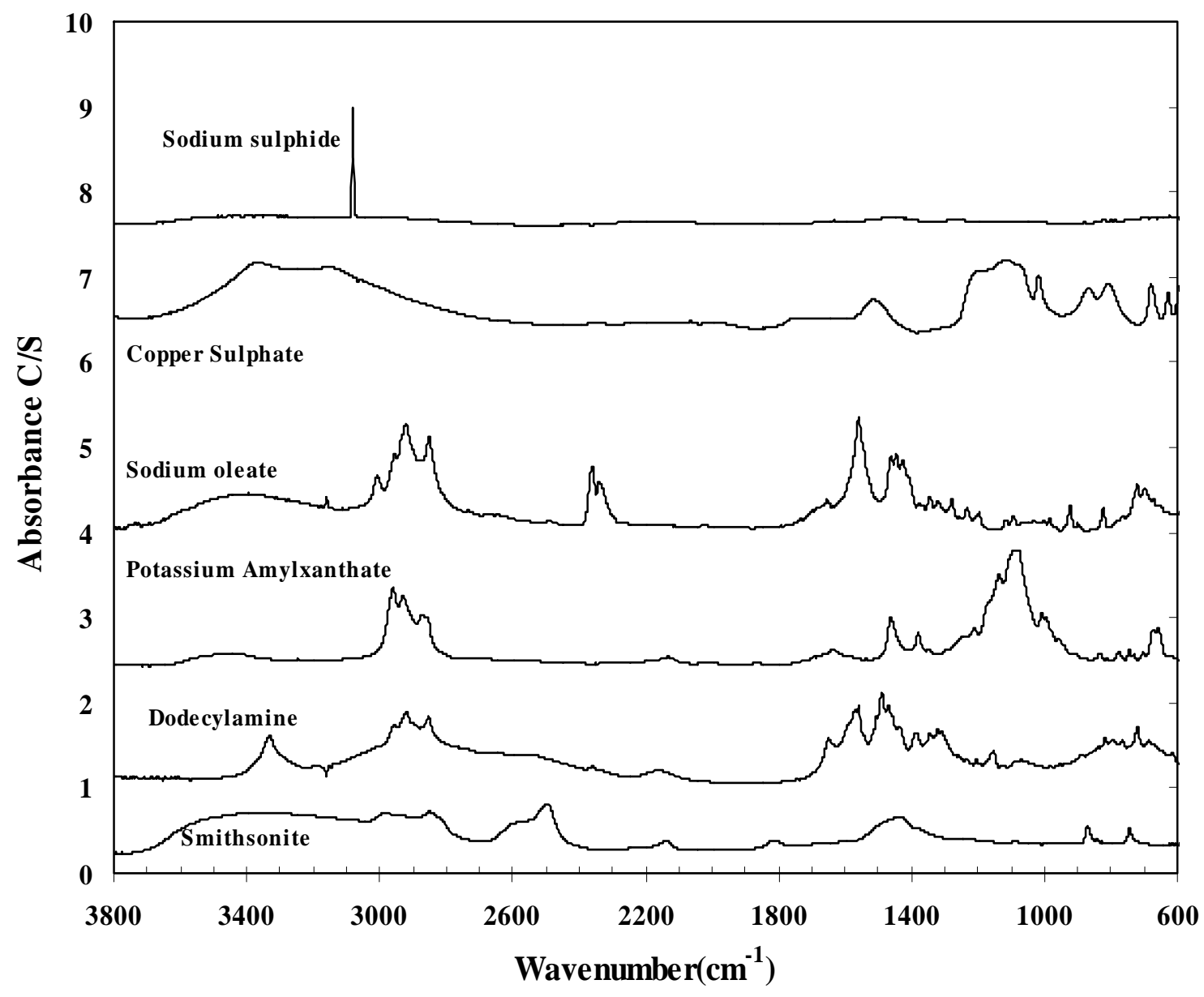

Fig. 1- Reference DRIFT IR-spectra of smithsonite, dodecylamine, KAX, sodium oleate, copper sulphate and sodium sulphide

The spectra exhibit intense absorption band corresponding to $v\left(\mathrm{NH}_{2}\right)$ in dodecylamine solution $\left(1.6 \times 10^{-3} \mathrm{M}\right)$ after sulphidising with sodium sulphide $\left(2.6 \times 10^{-2}\right.$ M). The reagent may be linked with $\mathrm{Zn}^{2+}$ ions through coordination bonds formed by $\mathrm{N}$ atoms and adsorbs to the smithsonite surface in the form of $\mathrm{Zn}$-amine complexes or perhaps the hydroxyl ions presents as zinc hydroxyl species on the surface of smithsonite [16-17]. 


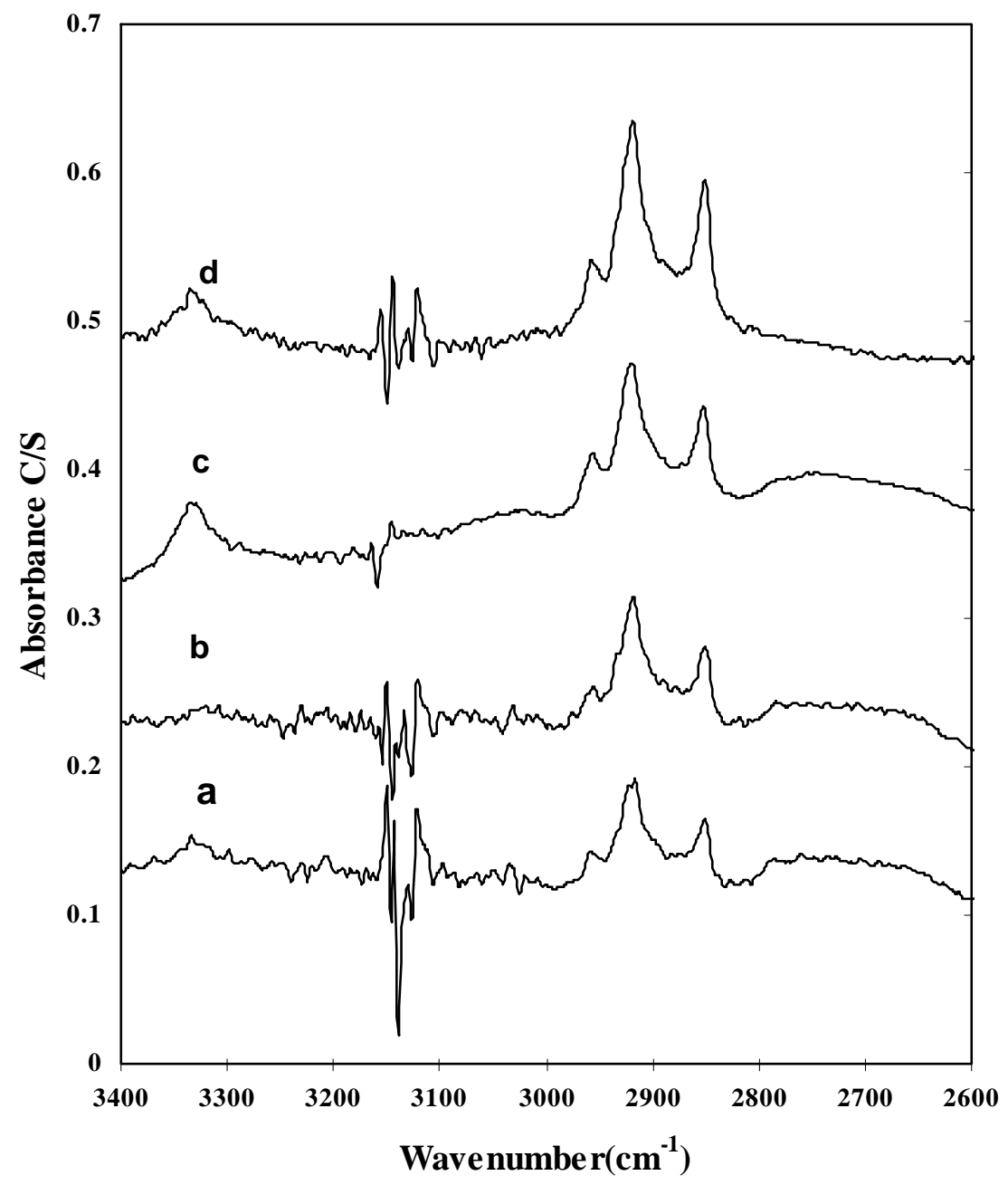

Fig. 2- FT-IR spectra of pure smithsonite treated with sodium sulphide solution $\left(2.6 \times 10^{-2} \mathrm{M}\right)$ at $\mathrm{pH} 11.5$ with increasing initial concentration of dodecylamine (a) $10^{-5} \mathrm{M}$ (b) $5.3 \times 10^{-4} \mathrm{M}$ (c) $1.1 \times 10^{-3}$ (d) $1.6 \times 10^{-3} \mathrm{M}$

Generally at the flotation $\mathrm{pH}$ of around 10 the $\mathrm{RNH}^{3+}$ is effectively absent and it can be assumes that the $\mathrm{RNH}_{2}$ becomes attached to the zinc on the surface in $\mathrm{ZnS}$ form through complexation bonds as follows [11]:

$$
\begin{aligned}
& \mathrm{CO}_{3} \text { orS } \quad\left(\mathrm{NH}_{2} \mathrm{R}\right)_{n} \\
& \mathrm{CO}_{3} \text { orS }-\mathrm{Zn} \\
& \mathrm{CO}_{3} \text { orS } \quad(\mathrm{OH})_{n}
\end{aligned}
$$


The area under the alkyl chain bands (3000-2800 cm-1) and the adsorption density of DDA as a function of DDA concentrations are shown in Fig. 3. The adsorption density was calculated according the measured specific surface area of smithsonite $\left(0.43 \mathrm{~m}^{2} / \mathrm{g}\right)$. The results of DDA adsorption study by means of DRIFT IR-spectra show the increasing DDA adsorption density with increasing initial concentration of dodecylamine from 0.63 $\mathrm{mg} / \mathrm{m}^{2}\left(10^{-5} \mathrm{M}\right)$ to $5.95 \mathrm{mg} / \mathrm{m}^{2}\left(1.62 \times 10^{-3} \mathrm{M}\right)$.

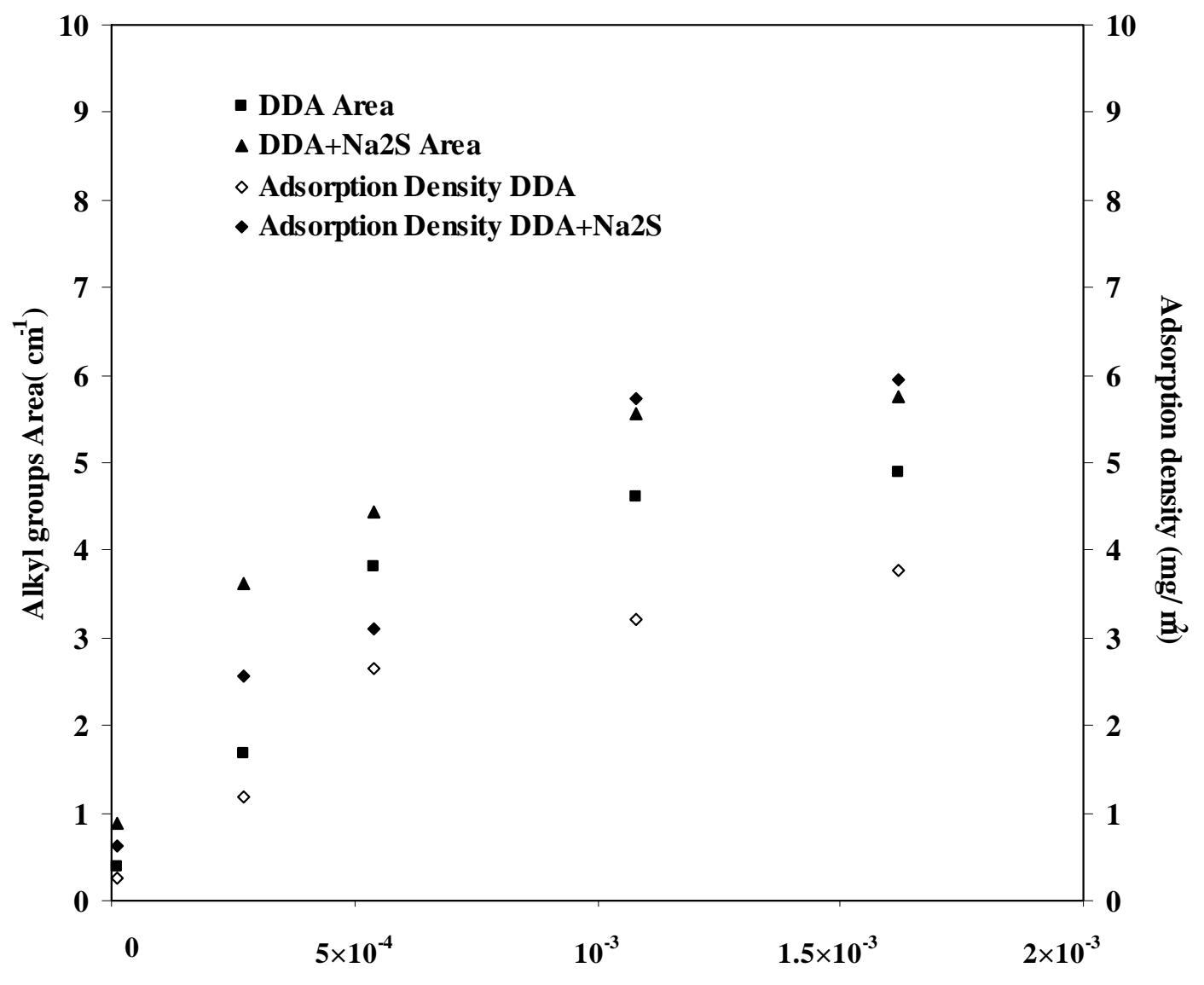

DDA concentration (mol/l)

Fig. 3- Adsorption density and area under alkyl chain bands $\left(2990-2800 \mathrm{~cm}^{-1}\right)$ of DRIFT IR-spectra of smithsonite as a function of dodecylamine concentration at $\mathrm{pH} 11.5$ in the presence or absence of sodium sulphide 


\section{Adsorption of Oleic Acid}

The peaks at 2924 and $2852 \mathrm{~cm}^{-1}$ [18-19] show that long alkyl chain is present in oleic acid treated smithsonite samples (Fig. 4). The appearance of peak $3411 \mathrm{~cm}^{-1}$ shows that $-\mathrm{OH}$ on the surface of smithsonite has not reacted completely.

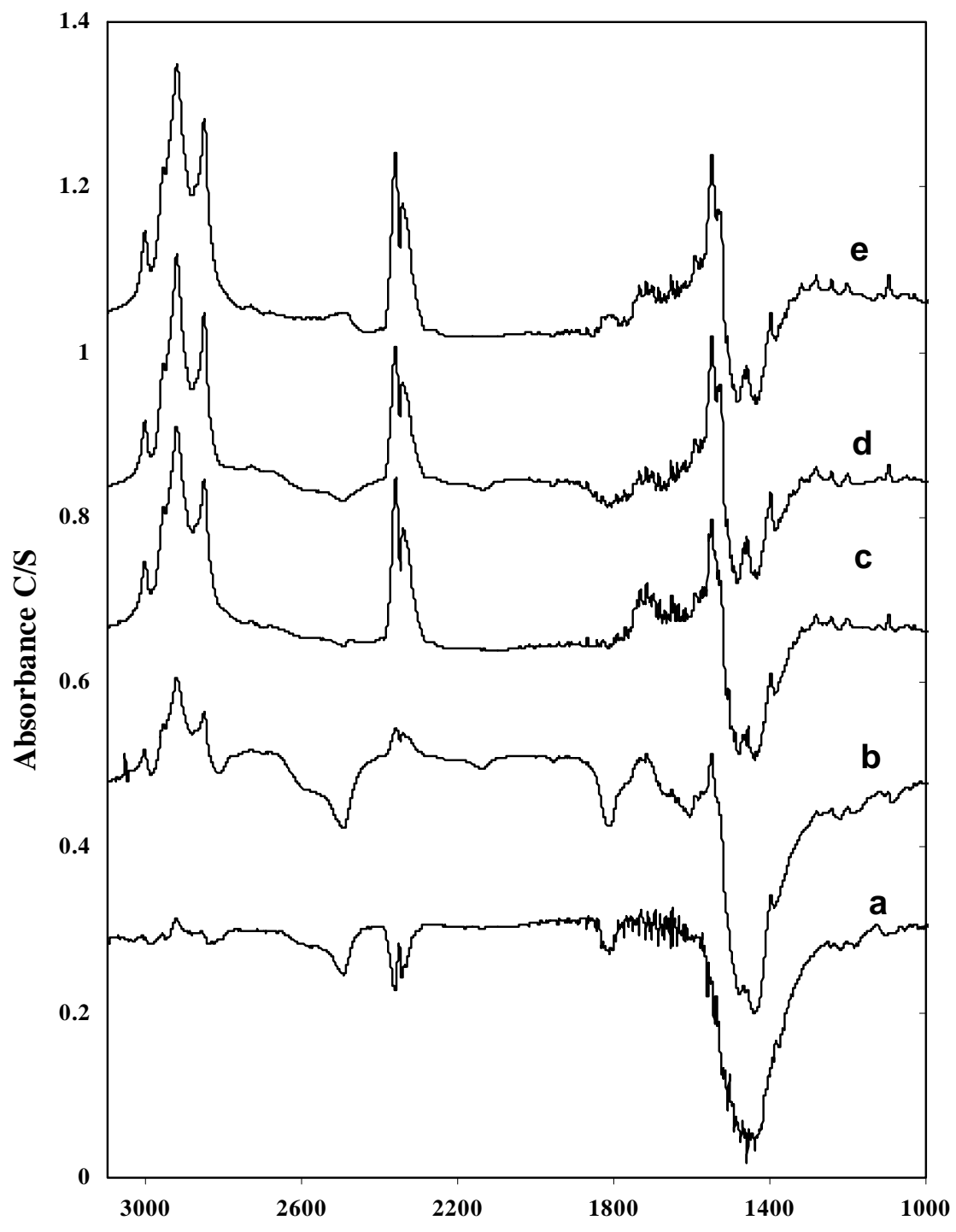

Fig. 4- DRIFT IR-spectra of pure smithsonite at $\mathrm{pH} 10$ with increasing initial concentration of oleic acid (a) $4.42 \times 10^{-5} \mathrm{M}$ (b) $1.77 \times 10^{-4} \mathrm{M}$ (c) $3.54 \times 10^{-4} \mathrm{M}$ (d) $5.31 \times 10^{-5} \mathrm{M}$ (e) $1.1 \times 10^{-3} \mathrm{M}$ 
It is known that $\mathrm{RCOOH}_{(1)}$ and $\mathrm{RCOOH}_{(\mathrm{aq})}$ are the predominant species, whereas species such as $\mathrm{RCOO}^{-},(\mathrm{RCOO})_{2}^{-2}$ and a lesser extent $\left[(\mathrm{RCOO}){ }_{2} \mathrm{H}\right]^{-}$exist in the basic region.

The maximum adsorption of oleic acid on smithsonite around $\mathrm{pH} 10$ may be attributed to interaction between $\mathrm{RCOO}^{-}$and zinc on the smithsonite surface and can be assumed that the adsorption of oleic acid takes place by an ion exchange mechanism as represented below:

$\mathrm{Zn}(\mathrm{OH})_{2 \text { (surf) }}+\mathrm{RCOO}^{-} \Leftrightarrow \mathrm{Zn}^{+} \mathrm{RCOO}^{-}+\mathrm{OH}^{-}$

Accordingly, the frequencies of the bands of carboxylate ion should show intermediate values between $v_{\mathrm{C}=\mathrm{O}}$ and $v_{\mathrm{C}-\mathrm{O}}$. Bands between $1538-1650 \mathrm{~cm}^{-1}$ and 1360 $1470 \mathrm{~cm}^{-1}$ were assigned due to asymmetric and symmetric stretching vibrations of carboxylate ion [20]. The asymmetric carboxylate vibration band may be attributed to chemisorbed oleate [21-22].

If the oleate is present in the form of undissociated oleic acid (-COOH), the mean frequency of $v_{\mathrm{C}=\mathrm{O}}$ stretching vibration should appear around $1690 \mathrm{~cm}^{-1}$ for dimmer and $1718 \mathrm{~cm}^{-1}$ for monomer. In the present investigation, the band around $1690 \mathrm{~cm}^{-1}$ and $1718 \mathrm{~cm}^{-1}$ was absent. It means that there is no dimmer adsorption. The broad band around $3411 \mathrm{~cm}^{-1}$ may be assigned to intermolecular hydrogen bonding of $\mathrm{H}_{2} \mathrm{O}$ molecules thus formed during adsorption.

The area under the alkyl chain bands $\left(3000-2800 \mathrm{~cm}^{-1}\right)$ and the adsorption density of oleic acid as a function of oleic acid concentrations are shown in Fig. 5. The results of oleic acid adsorption studies by means of DRIFT IR-spectra show the increasing oleic acid adsorption density with increasing initial concentration of oleic acid from 0.63 $\mathrm{mg} / \mathrm{m}^{2}\left(4.42 \times 10^{-5} \mathrm{M}\right)$ to $13.1 \mathrm{mg} / \mathrm{m}^{2}\left(1.1 \times 10^{-3} \mathrm{M}\right)$.

\section{Adsorption of KAX}

Figure 6 shows the FTIR spectra of smithsonite treated with different concentrations of KAX in the presence of sodium sulphide and copper sulphate solutions. Clearly in all obtained spectra the surface, the dixanthogen $(\mathrm{AX})_{2}\left(1270-1240 \mathrm{~cm}^{-1}\right)$ bands are missing. For all surface coverage values, the spectra exhibit absorption bands at $1041 \mathrm{~cm}^{-1}$, assigned to $\mathrm{C}=\mathrm{S}$ stretching mode $[3,18]$ and $1137 \mathrm{~cm}^{-1}$, characteristics of $\mathrm{C}-\mathrm{O}-\mathrm{C}$ stretching in dixanthogen [3]. The bands related to the hydrocarbon chain assigned at $2855,2955 \mathrm{~cm}^{-1}$ [18-19]. 


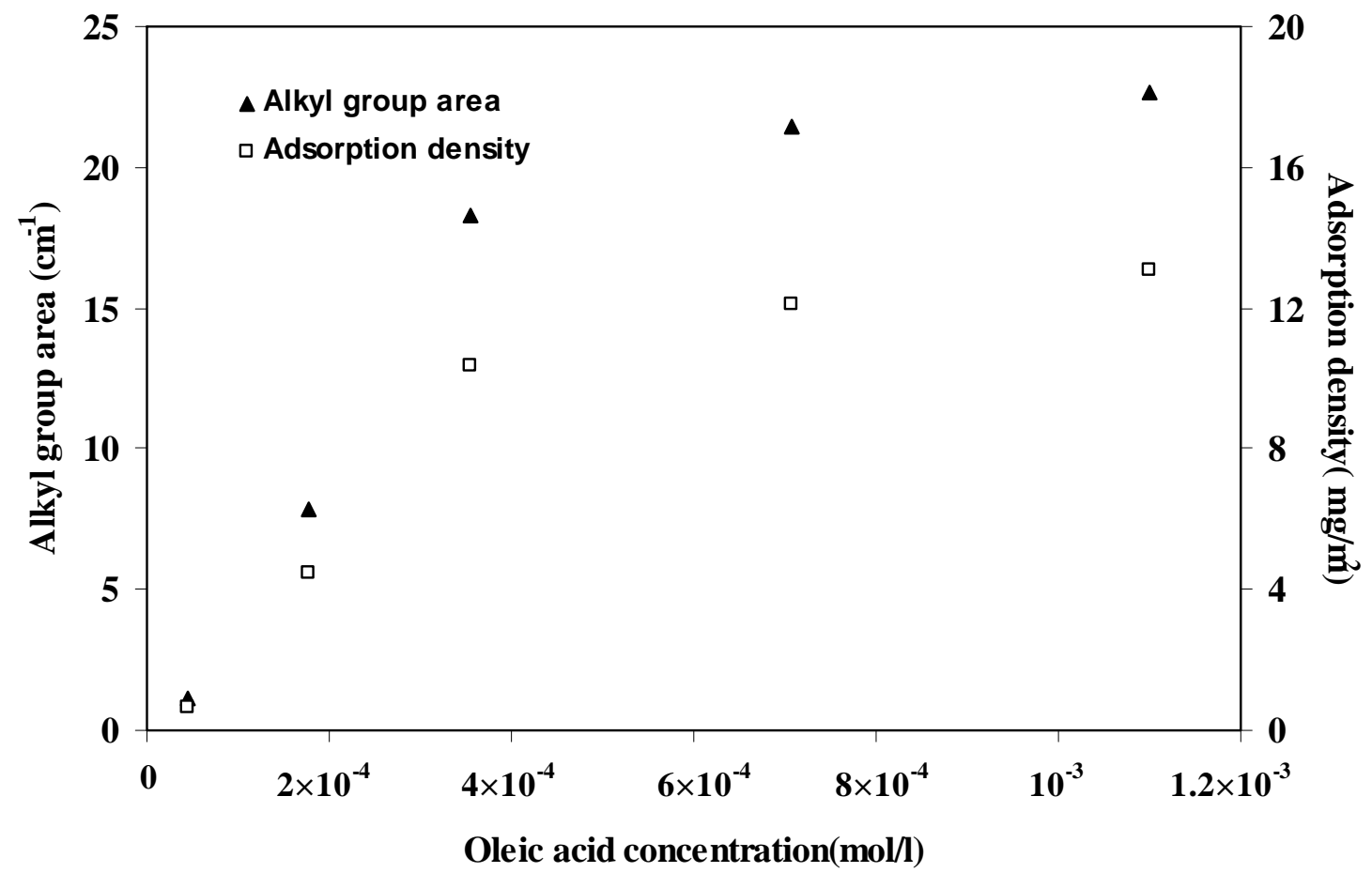

Fig. 5- Adsorption density and area under alkyl chain bands $\left(2990-2800 \mathrm{~cm}^{-1}\right)$ of DRIFT IR-spectra of smithsonite as a function of oleic acid concentration at $\mathrm{pH} 10$

The interaction of amylxanthate with the surface of smithsonite may be represented by the following reaction:

$$
\mathrm{ZnCO}_{3(\mathrm{~s})}+2 \mathrm{AX}_{(\mathrm{aq})}^{-} \Leftrightarrow \mathrm{ZnAX}_{2(\mathrm{~s})}+\mathrm{CO}_{3 \text { (aq) }}^{-2}
$$

It is pointed out that the similar equation was suggested for adsorption of xanthate on the cerussite surface by some researchers [23-24]. This ion-exchange reaction produces solid zinc xanthate at the mineral surface and releases carbonate ions to the solution. The area under the alkyl chain bands $\left(3000-2800 \mathrm{~cm}^{-1}\right)$ and the adsorption density of KAX as a function of KAX concentrations are shown in Fig.7.

The adsorption density was calculated according the measured specific surface area of smithsonite $\left(0.43 \mathrm{~m}^{2} / \mathrm{g}\right)$. The results of KAX adsorption study by means of DRIFT IRspectra show the increasing KAX adsorption density with increasing initial concentration of potassium amylxanthate from $0.35 \mathrm{mg} / \mathrm{m}^{2}\left(4.94 \times 10^{-4} \mathrm{M}\right)$ to $9.26 \mathrm{mg} / \mathrm{m}^{2}\left(2.96 \times 10^{-3} \mathrm{M}\right)$. 


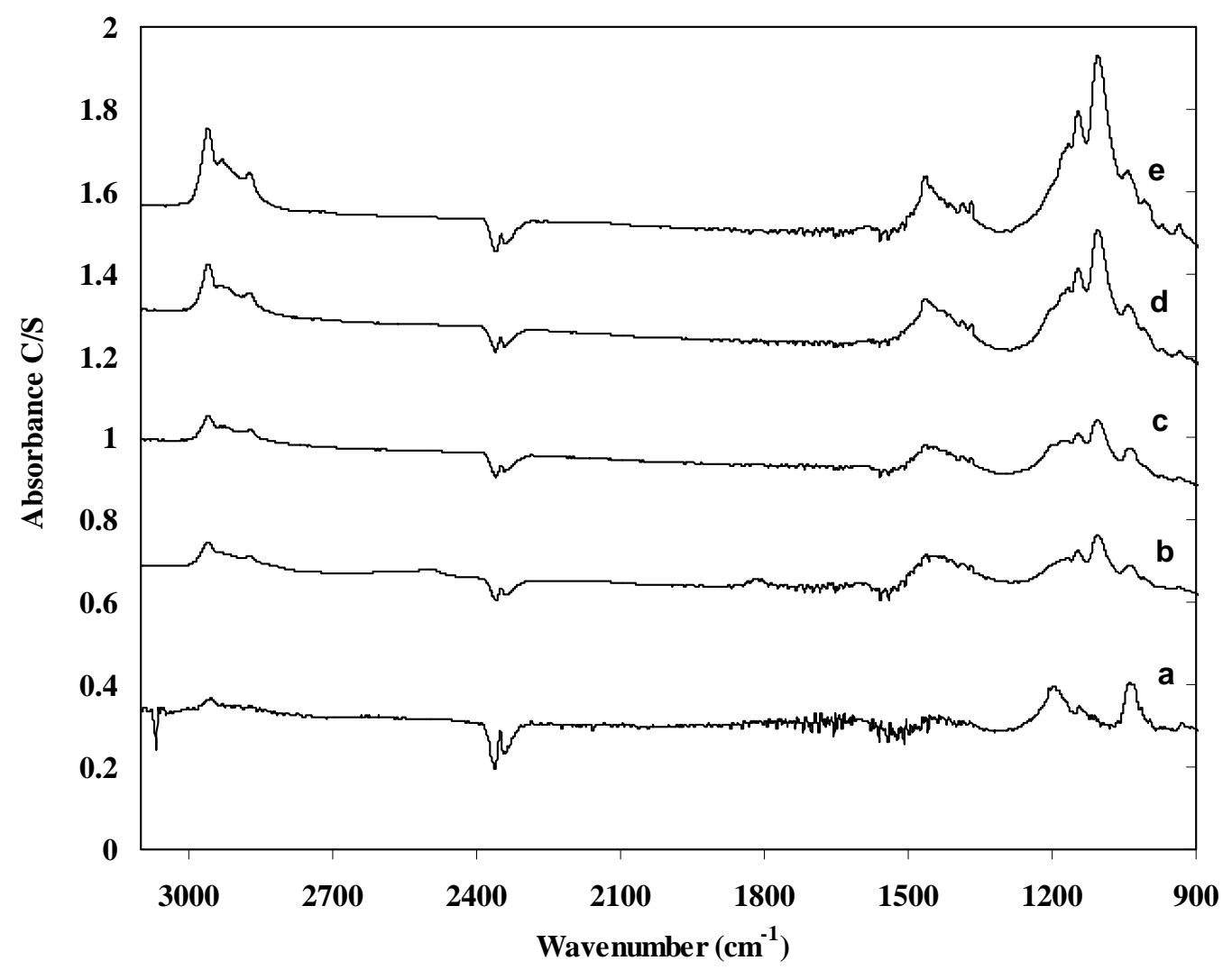

Fig.6- FT-IR spectra of pure smithsonite treated with sodium sulphide $\left(2.6 \times 10^{-2} \mathrm{M}\right)$ and copper sulphate $\left(9.4 \times 10^{-3} \mathrm{M}\right)$ at $\mathrm{pH} 10.5$ with increasing initial concentration of $\operatorname{KAX}$ (a) $4.94 \times 10^{-4} \mathrm{M}$ (b) $1.48 \times 10^{-3} \mathrm{M}$ (c) $1.98 \times 10^{-3} \mathrm{M}$

(d) $2.47 \times 10^{-3} \mathrm{M}$ (e) $2.96 \times 10^{-3} \mathrm{M}$

\section{X-ray Photoelectron Spectroscopy (XPS) Measurements}

\section{XPS Spectra of Pure Smithsonite}

The XPS spectral results of pure smithsonite demonstrate the appearance of the $\mathrm{Zn}$ (2p), C (1s) and O (1s). The Zn (2p) and C (1s) spectra of the smithsonite are presented in Fig. 8 .

The curve fitting unveiled that the $\mathrm{Zn}(2 \mathrm{p})$ spectra consist of two components, at 1022.1 and $1045.1 \mathrm{eV}$ which the both components are assigned to zinc in $\mathrm{ZnO}$ bond [25]. The C (1s) spectra shows the signal at $285,290 \mathrm{eV}$ which is assigned to carbon in C-O 
and $\mathrm{C}=\mathrm{O}$ in carbonate groups [26]. According to Fig. 8, the $\mathrm{O}$ (1s) spectra at $532 \mathrm{eV}$ which is relevant to $\mathrm{C}-\mathrm{O}$ and $\mathrm{C}=\mathrm{O}$ in carbonate groups [27]. The atomic percentage of XPS spectral results shows the element percent of Zn $17.11 \%$, C $6.65 \%$, and O $56.19 \%$.

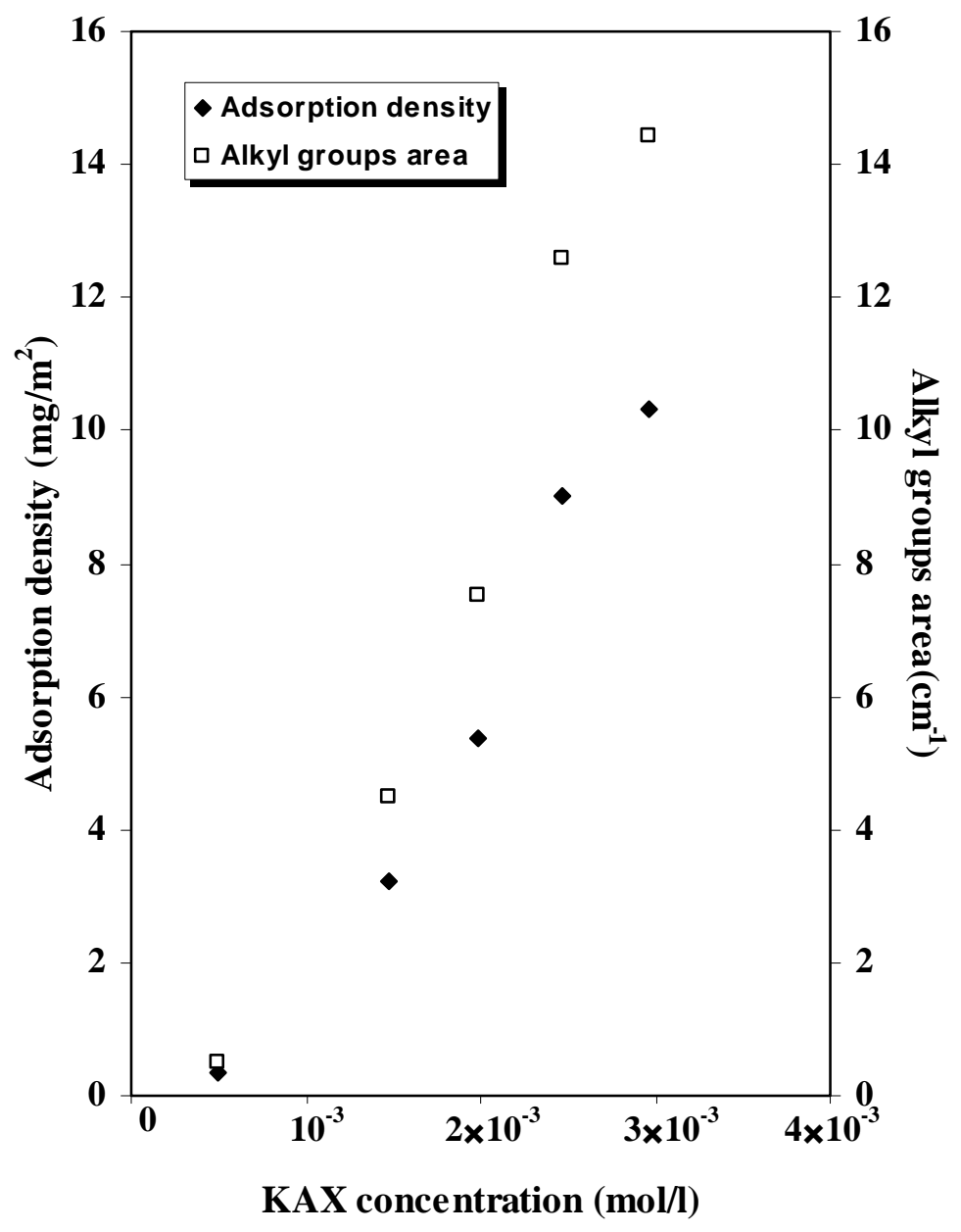

Fig. 7- Adsorption density and area under alkyl chain bands (2990-2800 cm-1) of IRspectra of smithsonite as a function of KAX concentration at $\mathrm{pH} 10.5$ in sodium sulphide $\left(2.6 \times 10^{-2} \mathrm{M}\right)$ and copper sulphate $\left(9.4 \times 10^{-3} \mathrm{M}\right)$ solutions 

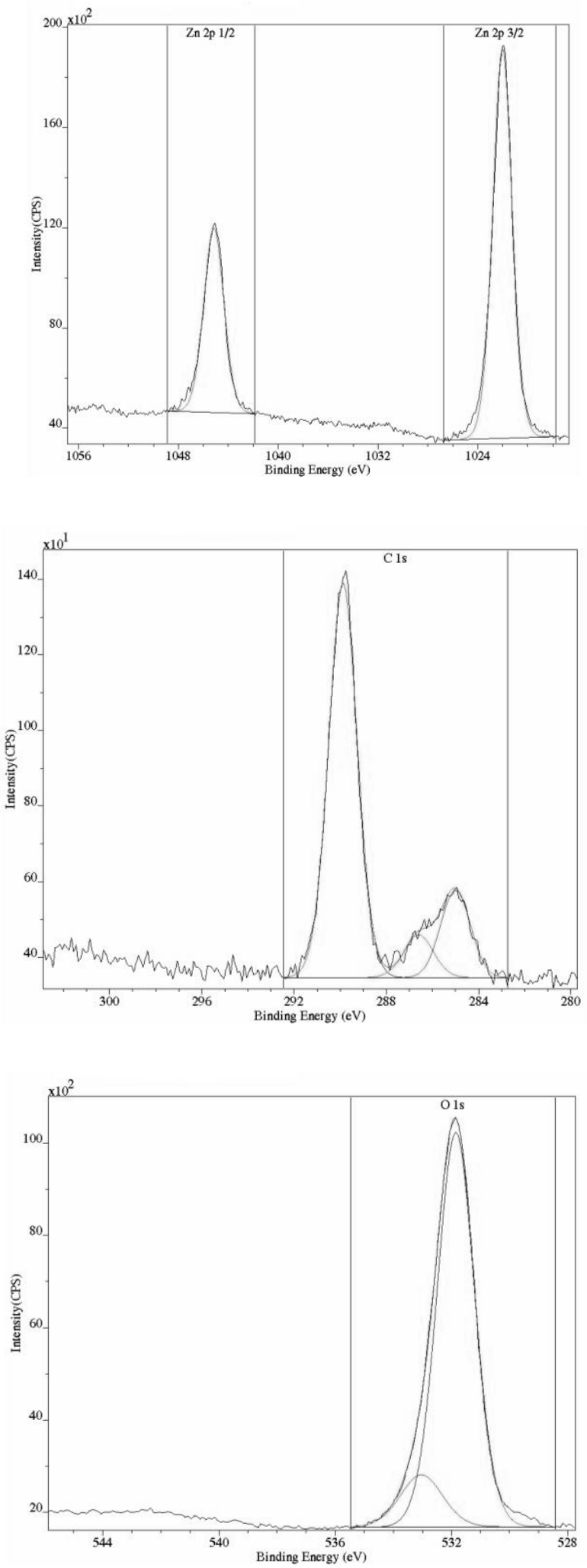

Fig. 8- XPS Zn (2p), C (1s) and O (1s) spectra of pure smithsonite 


\section{Adsorption of Dodecylamine}

XPS analysis of samples treated with DDA shows nitrogen to be present on the surface of sulphidised sample and this shows that DDA is present with the formation of DDA layer on the smithsonite surface. The $\mathrm{C}(1 \mathrm{~s}), \mathrm{N}(1 \mathrm{~s}), \mathrm{S}(2 \mathrm{p})$ spectra of the smithsonite treated with DDA $\left(1.62 \times 10^{-3} \mathrm{M}\right)$ are presented in Fig. 9 .

The curve fitting unveiled that the C (1s) spectra consists of two components, at 285 (reference peak) and $288.1 \mathrm{eV}$. The first component is assigned to carbon in $\mathrm{C}-(\mathrm{C}, \mathrm{H})$ bond and second one to the carbon in the $\mathrm{C}-\mathrm{N}[28]$.

The $\mathrm{N}$ (1s) signal of the amine groups at $399.6 \mathrm{eV}$ can be assigned to nitrogen in R$\mathrm{NH}_{2}$ bond and confirms the existent of DDA on the surface of mineral [29]. The $\mathrm{S}(2 \mathrm{p})$ spectra of pure sample conditioned with $1.62 \times 10^{-3} \mathrm{M}$ DDA show the broad peak at around $162.1 \mathrm{eV}$ confirms that $\mathrm{ZnS}$ is present on the mineral surfaces [30].

The XP spectra results of pure smithsonite conditioned with $\mathrm{Na}_{2} \mathrm{~S}\left(2.6 \times 10^{-2} \mathrm{M}\right)$ and DDA $\left(1.62 \times 10^{-3} \mathrm{M}\right)$ demonstrate the appearance of the $\mathrm{N}(1 \mathrm{~s})$ signal of the amine groups and $\mathrm{S}(2 \mathrm{p})$ signal of $\mathrm{ZnS}$ which increased in the intensity of the signal of $\mathrm{C}(1 \mathrm{~s})$ peak by adsorption of DDA on smithsonite with a simultaneous decrease in the peak intensities of oxygen.

Figure 10 shows the atomic percent of elements at the mineral surface. As it can be seen, there is increasing the carbon atomic percent after conditioning the pure mineral which show increasing the adsorption of DDA on the surface of mineral. The maximum adsorption occurs at the DDA concentration $\left(1.62 \times 10^{-3} \mathrm{M}\right)$. The $\mathrm{N}(1 \mathrm{~s})$ spectra and also the nitrogen atomic percent show the same total atomic concentrations of nitrogen at higher concentration of DDA.

Figure 11 shows the effect of dodecylamine conditioned on sulphidised smithsonite with $2.6 \times 10^{-2} \mathrm{M}$ of sodium sulphide.

The large increase in $\mathrm{O} / \mathrm{Zn}$ and $\mathrm{N} / \mathrm{Zn}$ values is noted with increasing the reagent concentration. There is always an excess of oxygen compared with that attributed to the smithsonite $\left(\mathrm{ZnCO}_{3}\right)$, as a result of both reagents used together. Initially the $\mathrm{S} / \mathrm{Zn}$ value decreases and then increases, which may be attributed to substitution of a pre-existing sulphide species. The small increase in $\mathrm{S} / \mathrm{Zn}$ may be due to the adsorption of dodecylamine.

\section{Adsorption of Oleic Acid}

The XPS C (1s) and O (1s) spectra of pure smithsonite conditioned in solution of oleic acid at $\mathrm{pH} 10$ are shown in Fig. 12. The C (1s) spectra consist of peaks $285 \mathrm{eV}$ (reference peak) and $290.2 \mathrm{eV}$, corresponding to alkyl and carboxylate carbon respectively. 

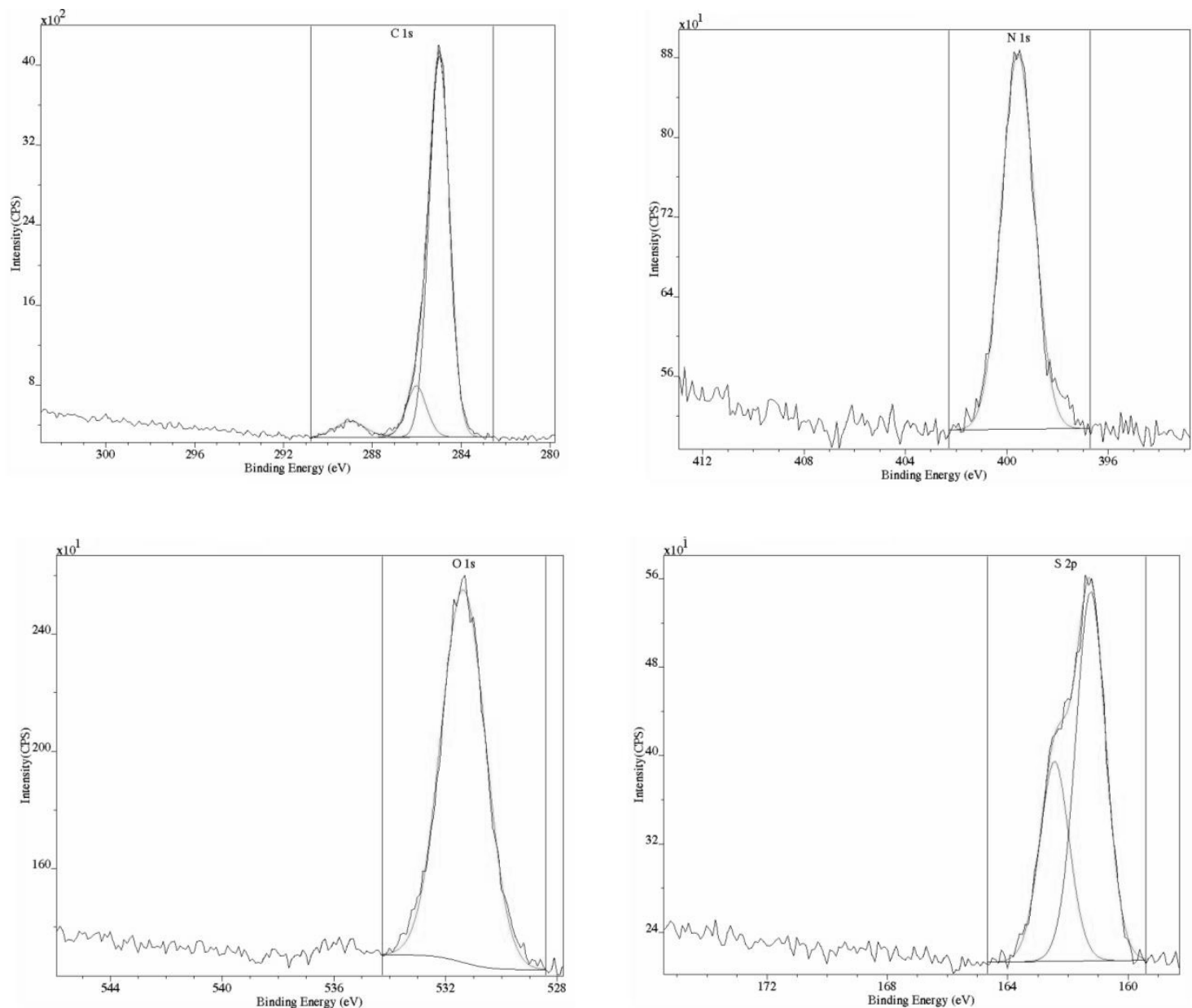

Fig. 9- XPS spectra of pure smithsonite conditioned in solution of DDA (pH 11) 


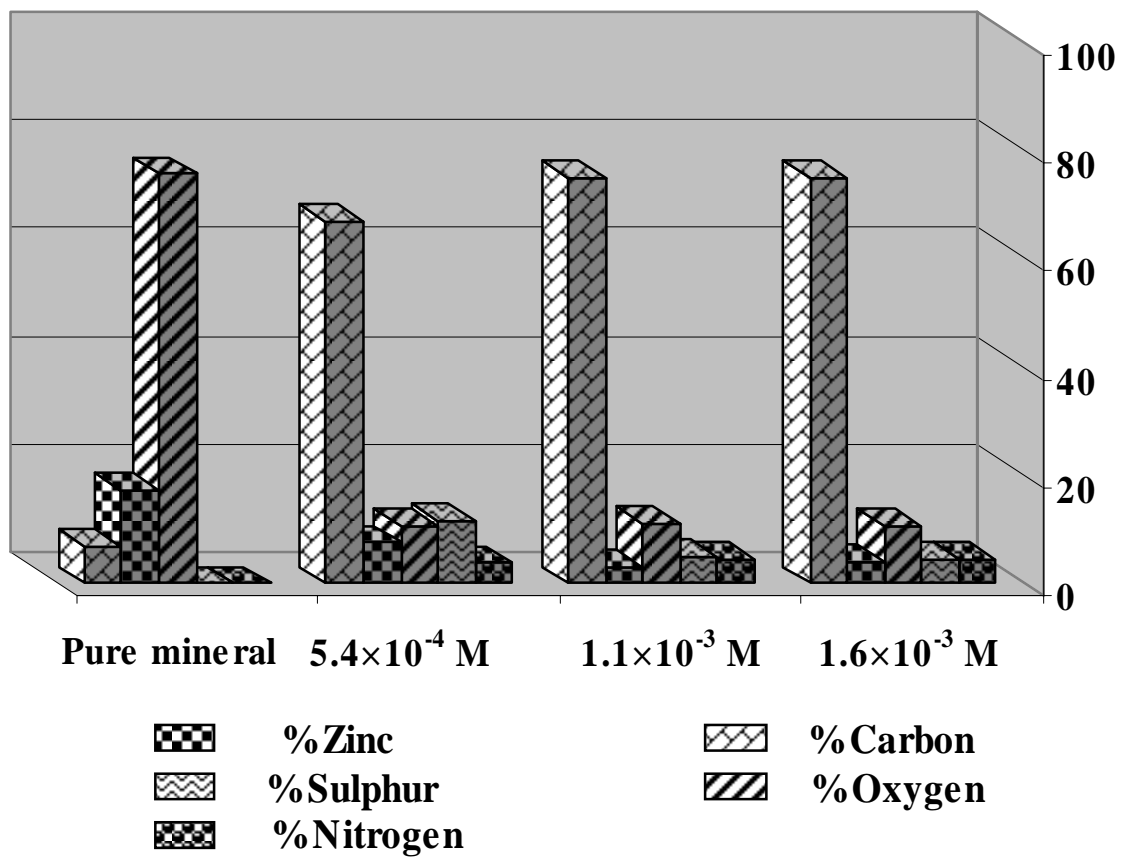

Fig. 10- Atomic percent elements on to smithsonite of surface after adsorption of DDA

The $\mathrm{O}(1 \mathrm{~s})$ spectra measured consist of the peak $533.5 \mathrm{eV}$, corresponding to $\mathrm{O}(1 \mathrm{~s})$ in carboxylate group [31]. It is obvious that the most adsorption occurs at around $\mathrm{pH} 10$ and this is because of the existence of $\mathrm{RCOO}^{-}$is predominant in solution and has interaction with mineral surface.

Figure 13 shows the atomic percent of elements at the mineral surface. As it can be seen, there is increasing the carbon atomic percent after conditioning the pure mineral which show increasing the existence of alkyl chain at the surface and conclusively increasing the adsorption of oleic acid on the surface of mineral. The maximum adsorption occurs for the OA concentration of $1.1 \times 10^{-3} \mathrm{M}$ at $\mathrm{pH} 10$. The XPS analysis of samples treated with oleic acid shows that OA is present with the formation of OA layer on the smithsonite surface. Fig. 14 shows the effect of oleic acid conditioned on pure smithsonite with $1.1 \times 10^{-3} \mathrm{M}$ of oleic acid. 


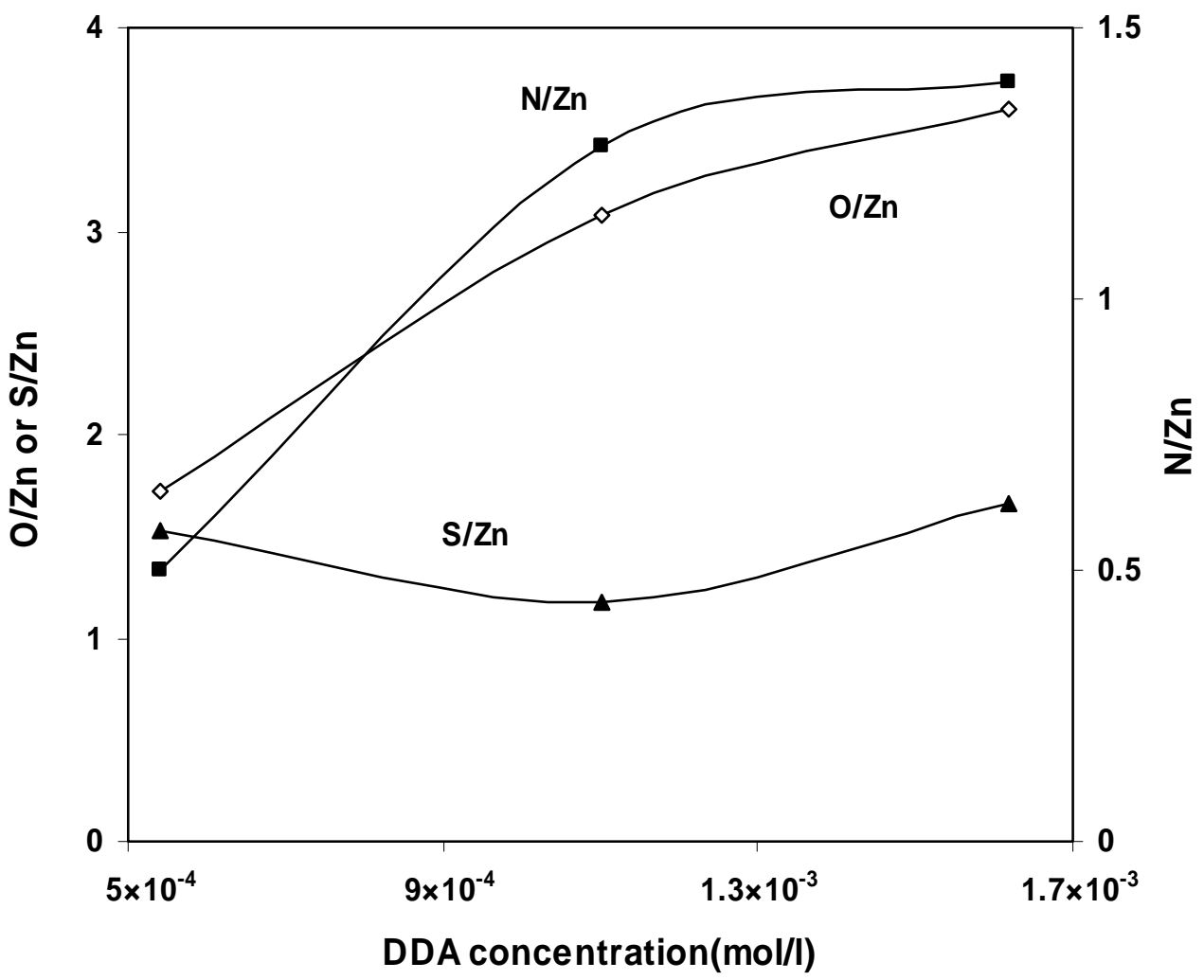

Fig. 11- The effect of DDA treatment on sulphidized smithsonite with $2.6 \times 10^{-2} \mathrm{M}$ of $\mathrm{Na}_{2} \mathrm{~S}$

The increase in $\mathrm{O} / \mathrm{Zn}$ and $\mathrm{C} / \mathrm{Zn}$ values with increasing the reagent concentration at $\mathrm{pH}$ 10 shows the increasing of carbon content regarding carbon chain in reagent. There is always an excess of oxygen compared with that attributed to the smithsonite $\left(\mathrm{ZnCO}_{3}\right)$, as a result of reagent used and the increasing of $\mathrm{Zn}$ content in media. 

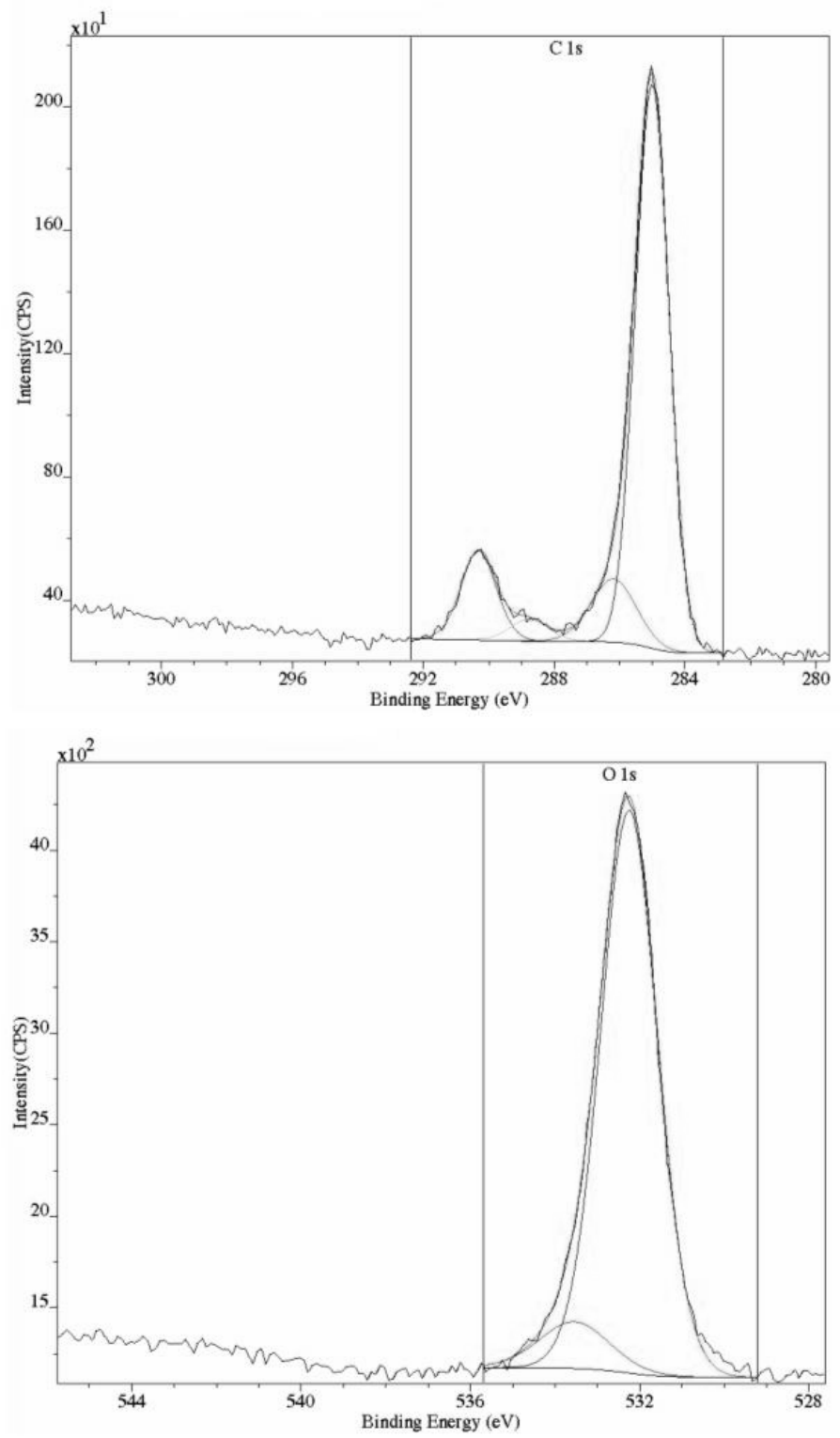

Fig. 12- XPS C (1s) and O (1s) spectra of pure smithsonite conditioned in solution of oleic acid ( $\mathrm{pH} \mathrm{10)}$ 


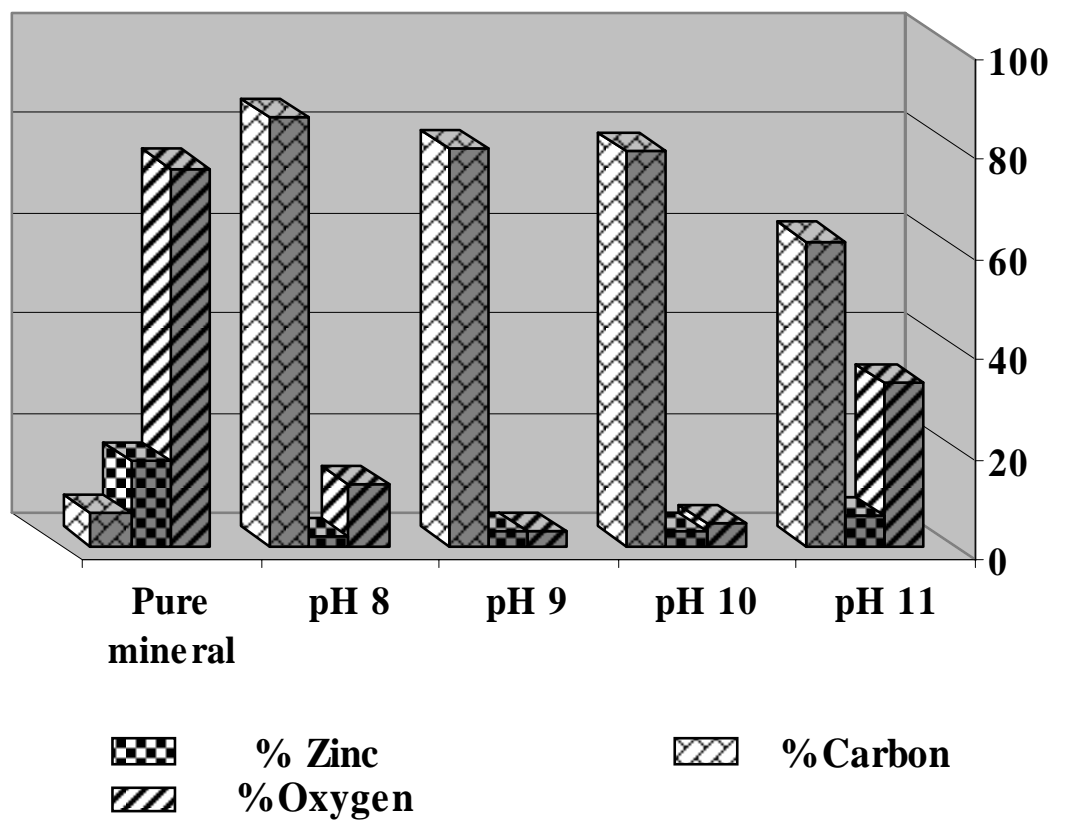

Fig. 13- Atomic percent elements on smithsonite surface after treatment with oleic acid $\left(1.1 \times 10^{-3} \mathrm{M}\right)$ 


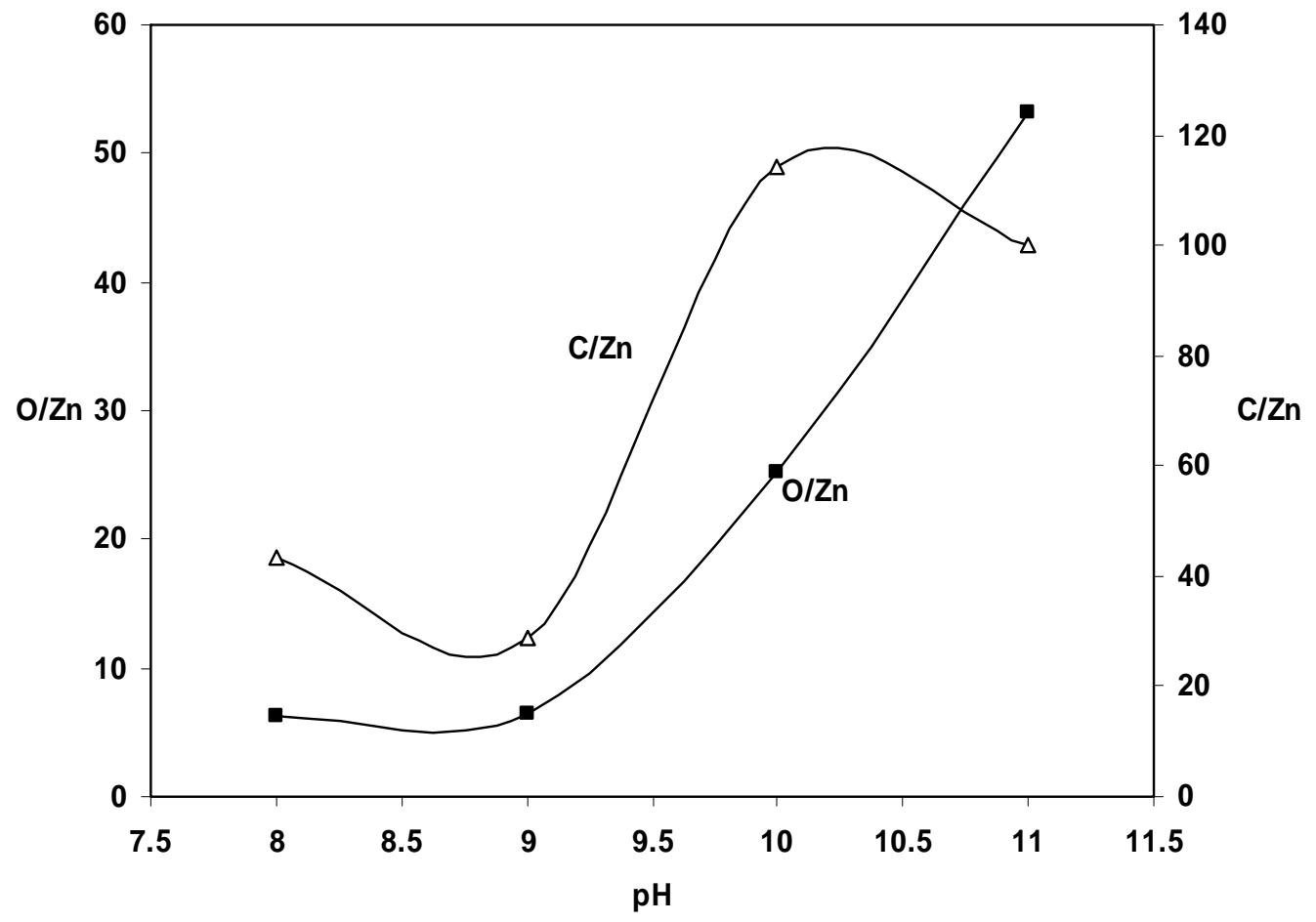

Fig. 14- The effect of oleic acid $\left(1.1 \times 10^{-3} \mathrm{M}\right)$ treatment on pure smithsonite at different $\mathrm{pH}$

\section{Adsorption of KAX}

The XPS C (1s), S (2p), O (1s) and $\mathrm{Cu}(2 \mathrm{p})$ spectral results of pure smithsonite conditioned in solution of $\operatorname{KAX}\left(2.96 \times 10^{-3} \mathrm{M}\right)$ at $\mathrm{pH} 10.5$ are illustrated in Fig. 15.

The C (1s) spectra consists of peaks $285 \mathrm{eV}$ (reference peak), 286.4 and $288.4 \mathrm{eV}$, corresponding to alkyl, $\mathrm{CS}_{2}$ and $\mathrm{CO}$ carbon respectively [32-33]. The intensity of characteristic peak in spectra for alkyl group (285.0) shows the increasing peak intensity in comparison to $\mathrm{C}(1 \mathrm{~s})$ spectra in pure smithsonite. It shows that there is adsorption to form a film at the surface of mineral. 

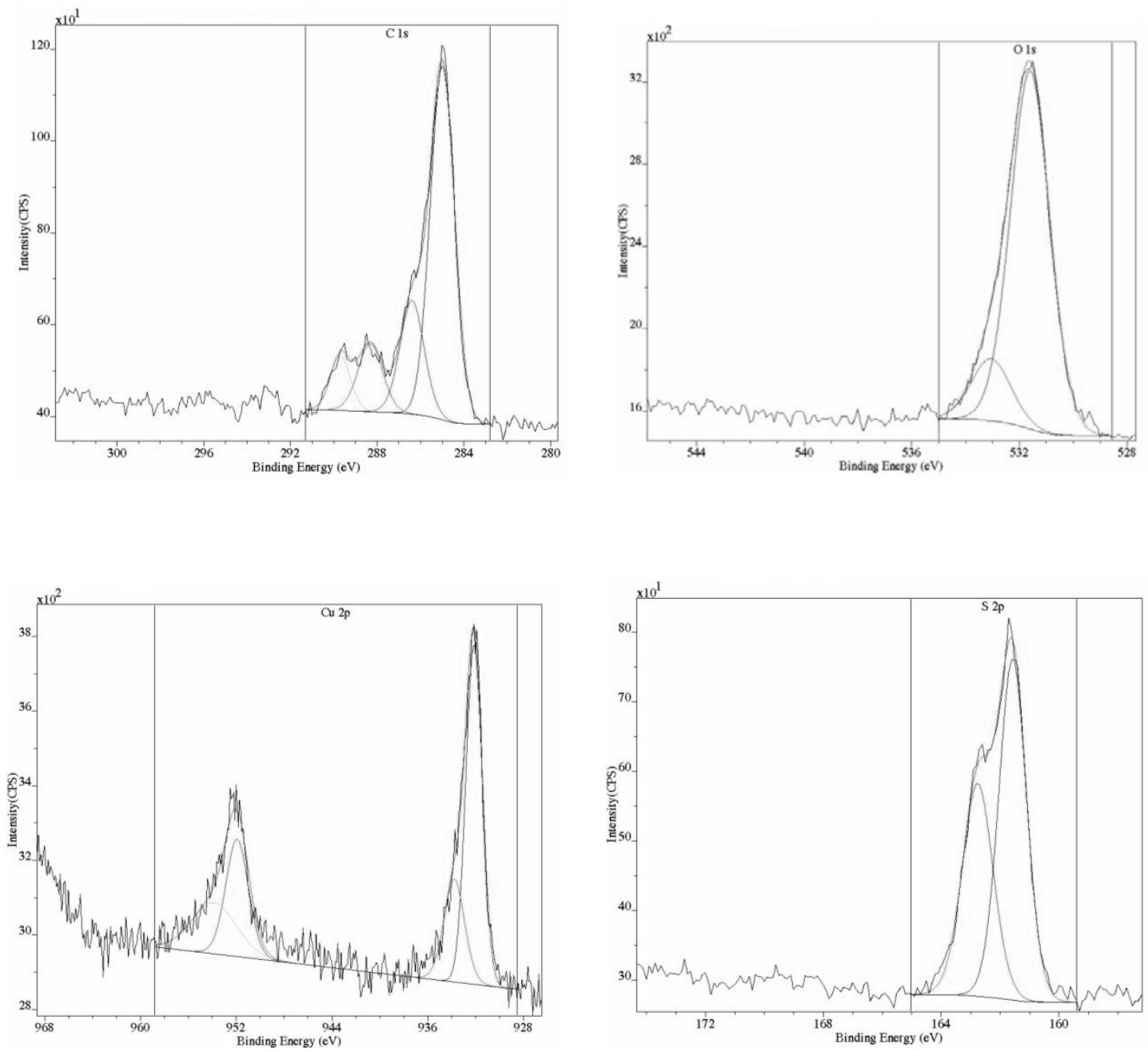

Fig. 15- XPS spectra of pure smithsonite conditioned in solution of KAX $\left(2.96 \times 10^{-3} \mathrm{M}\right)$ at $\mathrm{pH} 10.5$

The $S(2 p)$ spectra measured consists of the peak $161.6 \mathrm{eV}$, corresponding to $\mathrm{S}(2 \mathrm{p})$ in ZnS layer onto the mineral surface [34].

The changes in the $\mathrm{C} 1 \mathrm{~s}$ and $\mathrm{O} 1 \mathrm{~s}$ emissions during the adsorption treatment show that the adsorption of xanthate occurs. The detailed mechanism by which the exchange takes place is not clear and obviously cannot be concluded from the above observations. Slight changes in the positions and shapes of the components due to the xanthate group are observed during the adsorption process. 
The $\mathrm{Cu}(2 \mathrm{p})$ spectra measured consist of the peak $932.1 \mathrm{eV}$, corresponding to $\mathrm{Cu}(2 \mathrm{p})$ in $\mathrm{CuS}$ [34] and $952.3 \mathrm{eV}$, corresponding to $\mathrm{Cu}_{2} \mathrm{O}$ layer on the mineral surface [25]. The atomic concentration of the $\mathrm{Cu}$ peaks shows the more concentration for $\mathrm{CuS}$ in comparison of $\mathrm{Cu}_{2} \mathrm{O}$. It may be suggested that copper cations exchange with those of zinc during copper activation of smithsonite such as activation of sphalerite. Figure 16 shows the atomic percent of elements at the mineral surface before and after treating with KAX.

As it can be seen, there is increasing the carbon atomic percent and decreasing the oxygen content of mineral surface after conditioning which show increasing the existence of alkyl chain at the surface and conclusively increasing the adsorption of KAX on the surface of mineral. On the other hand, it can be observed the increasing the copper and sulphur percent of the surface with increasing the concentration of KAX in solution. This shows that the ion exchange of $\mathrm{Zn}^{2+}$ and $\mathrm{Cu}^{2+}$ and existence of $\mathrm{CuS}$ layer on the surface of mineral. The maximum adsorption occurs for the KAX concentration of $2.96 \times 10^{-3} \mathrm{M}$ at $\mathrm{pH}$ 10.5. The XPS analysis of samples treated with KAX shows that KAX is present with the formation of KAX layer on the smithsonite surface.

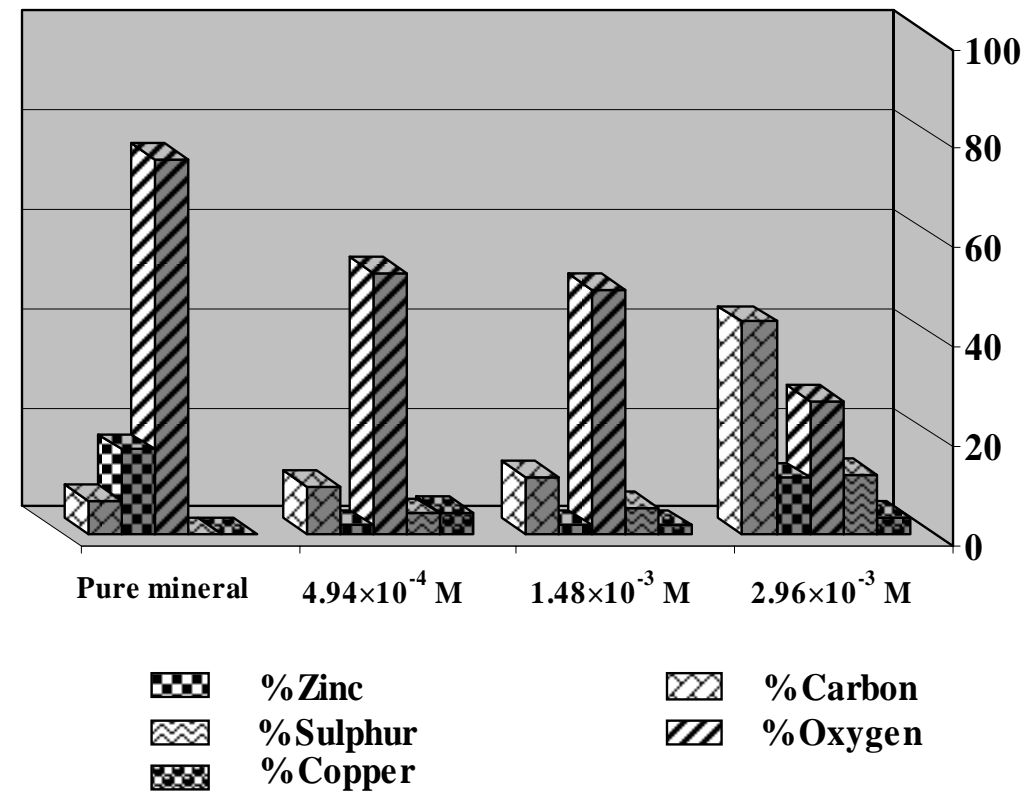

Fig. 16- Atomic percent elements on smithsonite surface after adsorption of KAX 


\section{CONCLUSIONS}

1. According to the results, the presence of $\mathrm{RNH}_{2}$ on the surface of smithsonite was confirmed. Hence, this is showed the adsorption of DDA onto smithsonite surface. XPS results confirmed the presence of $\mathrm{ZnS}$ layer on the surface after sulphidising in amine adsorption. The appearance of the N (1s) signal of the amine groups and S (2p) signal of $\mathrm{ZnS}$ which increased in the intensity of the signal of $\mathrm{C}(1 \mathrm{~s})$ peak by adsorption of DDA on smithsonite with a simultaneous decrease in the peak intensities of oxygen.

2. The FTIR spectra revealed the presence of $\mathrm{COO}^{-}$on the surface of smithsonite and this is confirmed the adsorption of OA onto surface. It is obvious that the most adsorption occurs at around $\mathrm{pH} 10$ and this is because of the existence of $\mathrm{RCOO}^{-}$is predominant in solution and has interaction with mineral surface.

3. Experimental findings showed the presence of $\mathrm{CS}_{2}$ on the surface of smithsonite and the adsorption of KAX onto surface. XPS results show the presence of ZnS layer on the surface after sulphidising and also the transferring the surface to $\mathrm{CuS}$ in KAX adsorption. It is suggested that copper cations exchange with those of zinc during copper activation of smithsonite such as activation of sphalerite.

\section{Acknowledgements}

We wish to thank Calcimine Co. for providing the samples, which were used in this investigation. The authors thank Dr. A. V. Shchukarev, Department of Inorganic Chemistry, Umeå University and also Mr. urban Jelvestam, Material Science Department, Chalmers university of Technology, Sweden, for the XPS measurements.

\section{References}

1. Billi, M., and Quai, V., 1963. Development and results obtained in the treatment of zinc oxide ores at AMMI mines", IMPC, London, paper 43.

2. Glembotskii, V. A., 1972. Flotation, primary sources, New York, pp.185-189.

3. Leja, J., 1982. Surface chemistry of froth flotation. Plenum Press, New York.

4. Rey, M., 1954. Flotation of Oxidized Zinc Ores. Mining Engineering.

5. Gaudin, A. M, 1957. Flotation. McGraw Hill Inc., New York, pp.182-189.

6. Weiss, N. L., 1985.SME Mineral Processing Handbook. AIME, pp. 15-4 15-7.

7. Rey, M., and Raffinot P., 1953. The flotation of oxidized zinc ores, Recent Developments in mineral dressing symposium. IMM, London.

8. McGarry, P. E., Pacic, Z., 1981. Flotation of Nonsulfide Zinc Materials. United States patent: 4253614. 
9. Ozbayoglu, G., Atalay, U., and Senturk, B., 1994. Flotation of lead and zinc carbonates ore. Recent advances in materials and mineral resources, Penang, Malaysia, pp.504-509.

10. Berry, Frank J., 1985. Mineral surfaces and Chemical bond, in Chemical bonding and spectroscopy in mineral chemistry. Frank J. Berry and David J. Vaughan (Ed.), London, Chapman and Hall, pp.293-315.

11. Marabini, A. M., Alesse, V., Garbassi, F., 1984. Role of sodium sulphide, xanthate and amine in flotation of lead-zinc oxidized ores. Inst of Mining \& Metallurgy, pp.125-136.

12. Farmer, V. C., 1974. The infrared spectra of minerals. Mineralogical society, pp.239.

13. Gadsden, J. A., 1975. Infrared Spectra of Minerals and Related Inorganic Compounds. Butterworth, pp.66.

14. Ferraro, John R., 1982. The Sadtler infrared spectra hand book of minerals and clays. Saddler.

15. Jones, G. C., Jackson, B., 1993. Infrared Transmission spectra of carbonate minerals. Chapman \& Hall, London.

16. Pascal, P., 1962. Complexes du zinc, " Nouveau traite de chimie minerale, Masson, Paris, pp.318-321.

17. Healy, T. W., and Moignard, M. S., 1976. A review of electrokinetic studies of metal sulfides, Flotation: A. M. Gaudin Memorial Volume, Fuerstenau M. C. (Ed.), AIME , New York, pp. 334-363.

18. Socrates, G., 1980. Infrared Characteristics Group Frequencies. John Wiley \& Sons, Ltd., New York.

19. Miller, J. D., and Kellar, J. J., 1999. Internal reflection spectroscopy for FTIR analysis of carboxylate adsorption by semi soluble salt minerals. Advances in Flotation Technology. Society for Mining, Metallurgy, and Exploration, Inc., Littleton, CO, pp.45-58.

20. Smith, B. C., 1998. Infrared Spectral Interpretation: A systematic Approach. CRC Press, Washington DC.

21. Gong, Wen Qi, Parentich, A., Little, L., H. and Warren, L. J., 1992. Adsorption of oleate on apatite studied by diffuse reflectance infrared Fourier transform spectroscopy. Lagmuir 8, pp. $118-124$.

22. Jang, Woo-Hyuk, Drelich, J., and Miller, Jan D., 1995. Wetting Characteristics and Stability of Langmuir-Blodgett Carboxylate Monolayers at the Surfaces of Calcite and Fluorite. Langmuir 11, pp.3491 - 3499.

23. Fleming, M. G., 1953.Effect of soluble sulphide in the flotation of secondary lead mineral. Trans. IMM, London, pp.521-554.

24. Fuerstenau, D. W., Stoillo, F., Valdivieso, A., 1985a.Sulfidization and flotation behaviour of anglesite, cerussite and galena. Proceeding. XV International Mineral Processing Congress, Cannes, France, pp.74-86.

25. Maroie, S. Haemers, G. Verbist, J. J., 1984.Surface oxidation of polycrystalline "alpha" ( $75 \% \mathrm{Cu}$ et 25\% Zn ) and "beta" ( $53 \% \mathrm{Cu}$ et $47 \% \mathrm{Zn}$ ) brass as studied by XPS : influence of oxygen pressure. Applications of Surface Science,Vol.17, pp.463476. 
26. Bichler, C. H., Bischoff, M., Langowski, H.-C., Moosheimer, U., 1996. The Substrate-Process Interface in Thin Barrier Film Coating. 39th Annual Technical Conference of the Society of Vacuum Coaters, Philadelphia.

27. Bou, M., Martin, J. M., Le Mogne, T. H., Vovelle, L., 1991. Chemistry of the interface between aluminium and polyethyleneterephtalate by XPS. Applied Surface Science, Vol. 47, pp.149-161.

28. Delpeux, S., Beguin, F., Benoit, R., Erre, R., Manolova, N., Rashkov, I., 1998.Fullerene core star-like polymers-1. Preparation from fullerenes and monoazidopolyehers.Eur. Polym. J., Vol. 34, No.7, pp.905-915.

29. Lim, A. S., Atrens, A., 1990. ESCA studies of Nitrogen-Containing Stainless Steels. Applied Physics A, Vol. 51, pp. 411-418.

30. Brion, D., 1980, "Etude par spectroscopie de photoélectrons de la dégradation superficielle de $\mathrm{FeS} 2, \mathrm{CuFeS} 2, \mathrm{ZnS}$ et $\mathrm{PbS}$ à l'air et dans l'eau", Applications of Surface Science, Vol 5, pp.133-152.

31. Clark, D. T., Thomas, H. R., 1978.Applications of ESCA to polymer Chemistry, XVII. Systematic Investigation of the Core Levels of Simple Homopolymers, Journal of Polymers Science, Polymer Chemistry Edition, Vol. 16, pp. 791-820.

32. Liao, H. M., Sodhi, R. N. S., Coyle, T. W., 1993. Surface composition of Al N powders studied by x-ray photoelectron spectroscopy and bremsstrahlung-excited Auger electron spectroscopy. J. Vac. Sci. Technol. A, Vol. 11, No. 5, pp.2681-2686.

33. Wagner, C.D., Riggs, W. M., Davis, L. E., Moulder, G. F., 1979. Handbook of X-ray photoelectron spectroscopy, Minnesota, Perkin -Elmer Corporation.

34. Briggs, D., Seah, M. P., 1993. Practical surface analysis, John Wiley \& sons. Vol. 1, $2^{\text {nd }}$ edition. 